\title{
Factors associated with low handgrip strength in older people: data of the Study of Chronic Diseases (Edoc-I)
}

Cledir de Araújo Amaral ${ }^{1 *}$, Thatiana Lameira Maciel Amaral², Gina Torres Rego Monteiro³, Maurício Teixeira Leite de Vasconcellos ${ }^{4}$ and Margareth Crisóstomo Portela ${ }^{5}$

\begin{abstract}
Background: Handgrip strength (HGS) is an important health biomarker whose low scores have been shown to be associated with the morbimortality. This study aimed to analyze the factors associated with low HGS in older people in Rio Branco, Acre, Brazil.

Methods: The study was carried out with data from the Study of Chronic Diseases (EDOC-I) - Older People, a crosssectional household PAPI probability sample survey performed with 1016 people aged over 60 residing in Rio Branco in 2014. The low HGS was defined by the 20th percentile of the maximum HGS by sex and age group. Associations between variables of health status (psychological and physical) and low HGS, by sex, were estimated using logistic regression, expressed by adjusted ORs (aOR).

Results: Older individuals had lower median HGS than younger individuals ( $-6.0 \mathrm{~kg}$ among men and $-2.6 \mathrm{~kg}$ among women). Women aged over $80 \mathrm{had}$, on average, the lower quintile of HGS compared to women of the previous age groups. Factors independently associated with low HGS in men and women, respectively, were low weigh in body mass index $[(\mathrm{aOR}=2.80 ; 95 \% \mathrm{Cl}: 1.19,6.61)$ and $(\mathrm{aOR}=2.61 ; 95 \% \mathrm{Cl}: 1.46,4.66)]$, anemia $[(\mathrm{aOR}=4.15$; 95\%Cl: $2.09,8.21)$ and $(\mathrm{aOR}=1.80 ; 95 \% \mathrm{Cl}: 1.06,3.06)]$ and diabetes as a risk factor in men (aOR 1.95; 95\%Cl: 1.00, 3.81). There was a higher chance of low HGS in men with partners ( $\mathrm{aOR}=2.44 ; 95 \% \mathrm{Cl}: 1.32,4.51$ ), smokers or former smokers ( $\mathrm{aOR}=3.25 ; 95 \% \mathrm{Cl}: 1.25,8.44)$, with current self-assessment of health worse than the 12 previous months $(\mathrm{aOR}=2.21 ; 95 \% \mathrm{Cl}: 1.14,4.30)$ and dependence in activities of daily living $(\mathrm{aOR}=2.92 ; 95 \% \mathrm{Cl}: 1.35,6.30)$. Only among women, there was an increased chance of low HGS associated with altered waist-to-hip ratio ( $\mathrm{aOR}=1.79$; $95 \% \mathrm{Cl}: 1.02,3.12)$, insomnia (aOR $=1.83 ; 95 \% \mathrm{Cl}: 1.10,3.03)$ and physical activity from displacement/occupation $(\mathrm{aOR}=1.75 ; 95 \% \mathrm{Cl}: 1.08,2.84)$.

Conclusion: Factors associated with low HGS are not the same between sexes, and the inclusion of HGS as a component of health assessment seems to be a promising strategy for disease prevention and health promotion.
\end{abstract}

Keywords: Hand strength, Insomnia, Diabetes mellitus, Anemia, Dependent elderly, Elderly's health, Epidemiological survey

\footnotetext{
* Correspondence: cledir.amaral@ifac.edu.br

${ }^{1}$ Federal Institute of Education, Science and Technology of Acre, Rio Branco, AC, Brazil

Full list of author information is available at the end of the article
}

(c) The Author(s). 2020 Open Access This article is licensed under a Creative Commons Attribution 4.0 International License, which permits use, sharing, adaptation, distribution and reproduction in any medium or format, as long as you give appropriate credit to the original author(s) and the source, provide a link to the Creative Commons licence, and indicate if changes were made. The images or other third party material in this article are included in the article's Creative Commons licence, unless indicated otherwise in a credit line to the material. If material is not included in the article's Creative Commons licence and your intended use is not permitted by statutory regulation or exceeds the permitted use, you will need to obtain permission directly from the copyright holder. To view a copy of this licence, visit http://creativecommons.org/licenses/by/4.0/. The Creative Commons Public Domain Dedication waiver (http://creativecommons.org/publicdomain/zero/1.0/) applies to the data made available in this article, unless otherwise stated in a credit line to the data. 


\section{Background}

Population aging is a worldwide phenomenon accompanied by the incidence of physical limitations that result in decreased quality of life and increased health care costs. These limitations pose higher risks of falls, institutionalization, comorbidities, and premature mortality. The loss of muscle mass and strength contributes significantly to physical incapacities in aging [1].

Musculoskeletal functionality plays an important role in health and disease, and it is influenced by age [2]. In the aging process, the capacity of the locomotor system and the secretory function of myosin, which act on the metabolism, is reduced, as well as the function of the muscular tissue and other tissues and organs [3], causing a reduction of muscle strength. The evaluation of such strength gains importance. Therefore, as an indicator of muscular quality and functionality, low muscle strength represents a significant public health problem [4].

Handgrip strength (HGS) is a means of measuring muscle strength that has been used to evaluate important health outcomes in older people [5]. Low HGS is associated with sarcopenia and plays an important role in the definition of the frailty phenotype [6]. It is also associated with falls, reduced functional autonomy, and musculoskeletal complaints [7]. The association between reduced HGS and the presence of depression [8], insomnia, diabetes, hypertension, cardiovascular diseases, multimorbidity [4, 7], and mortality [1] has also been demonstrated.

Further, a relation of HGS with indicators of social inequalities, demographic and behavioral conditions has been reported [4].

HGS as a means of tracking diseases and health problems favors the adoption of disease protection and health promotion actions in order to minimize the impacts of morbidity and mortality of the population. However, more knowledge needs to be consolidated to understand the relationship between HGS and morbidity, considering the possibility of these relationships to vary across different population groups. Only then, its use as a health biomarker can be ratified, and conditions of its applicability can be consistently defined.

In order to contribute to the construction of this knowledge, the objective of this study was to analyze the factors associated with low handgrip strength in older people in the City of Rio Branco, Acre, the northern region of Brazil.

\section{Methods}

\section{Study setting}

This is a secondary analysis of data from the Study of Chronic Diseases in Older People (Estudo das Doenças Crônicas em Idosos - EDOC-I), a household survey conducted between April and September 2014, with older people (60 years old or older) living in urban and rural areas of Rio Branco City, Acre State, Brazil. Rio Branco is located in the Western Brazilian Amazon. The Brazilian Institute of Geography and Statistics (IBGE) estimated that, on July 1, 2014, the older population (over 60 years old) corresponded to about $10 \%$ of the adult population (over 18 years old), with older women representing $53.5 \%$ of the total older population [9].

\section{Patients/sample}

Individuals with compromises that hindered communication or the understanding of the questions were excluded from the research population. Cluster sampling plans were selected in two stages, Census Enumeration Area (CEA) and household. The selection of the CEAs was made with a probability that was proportional to their number and private households in the 2010 Demographic Census (CD2010) of the IBGE. Households were selected by systematic sampling with random starts and distinct intervals. All older people present in the selected households were interviewed.

\section{Sampling}

The EDOC-I included 1016 older people interviewed. However, 50 subjects of the effective sample did not have HGS measurement, resulting in a sub-sample that had its sample weights corrected and recalibrated to produce estimates for 23,416 older people. Further details of the sampling plan of the EDOC-I, calculation, and calibration of the weights of the sample and subsamples are found in Amaral et al. [9].

\section{Measurements}

Household interviews were conducted with the study participants who answered a structured questionnaire covering socioeconomic, demographic, lifestyle, and health aspects. The trained interviewers evaluated anthropometric measurements and clinical conditions.

\section{Dependent variable}

Handgrip Strength (HGS) was measured, in kilograms (kg), using a SAEHAN SH5001 $1^{\circ}$ brand hydraulic hand dynamometer with a resolution of $2 \mathrm{~kg}$, following procedures adopted by the American Society of Hand Therapists previously showed [10]. Measurements were obtained in standardized conditions, with the participants in the seated position, elbow at $90^{\circ}$, and the handle adjusted to the second position. After receiving explanation of the procedures and after familiarizing then with the instrument, they applied the maximum grip strength for 3 to $5 \mathrm{~s}$. The procedure was performed three times with each hand alternately, with an interval of one minute between each measurement. The maximum HGS was identified considering the highest HGS value 
among six measures, regardless of the individual hand dominance.

\section{Covariates - sociodemographic}

Physical activity was analyzed in three aspects: physical activity in displacement - considering active the individual who moved to school or to work walking or using a bicycle whose time to go and return was more than 10 min; occupational physical activity - considering active the subject who reported carrying weights or walking intensely in their jobs or who did the house cleaning alone or, in case of receiving help, being the ones responsible for the most massive part of the cleaning; and physical activity in leisure - considering active those who reported practicing exercises or sports in the last three months with a minimum duration of $150 \mathrm{~min}$ per week in the case of moderate activities, or 75 min a week in vigorous activities.

Smoking was initially defined into three categories, including current smokers (those who smoke every day), former smokers (those who used to smoke every day), and non-smokers. Since it was not identified any significant difference between the two first groups, they were aggregated and compared to non-smokers.

Only current alcohol use was considered, although data were also collected on abusive use (binge drinking) in the last 30 days. Due to the low frequency of abusive use reported, the analysis was based on user vs. non-user.

\section{Covariates - clinical factors}

The investigation of functional independence was based on Katz's Modified Activities of Daily Living (ADL) scale and the Instrumental Activities of Daily Living (IADL) scale, as described previously [9]. Older people scoring less than five points in the ADL scale was considered as dependent in this analysis, as well as those who needed help for at least one of the activities addressed in the IADL scale.

The Geriatric Depression Scale (GDS-15) was used to assess the presence of depression, considering scores above five points as suggestive of depression [11].

In the definition of morbidities, musculoskeletal complaints were considered based on the self-report of the presence of "much" or "very much" pain in the joints or limbs, in the back, neck or shoulders, or based on reports of diagnoses of arthritis, arthrosis, tendonitis, and repetitive strain injury or osteoporosis. Cardiovascular events were defined by the occurrence of cerebrovascular accident, infarction or angina, heart failure, and arrhythmias or atrial fibrillation. Insomnia (trouble sleeping) was also identified by the self-report of its occurrence (possible answers: "yes" or "already had" or "no").

Other morbidities were defined based on laboratory test results of blood samples: anemia (hemoglobin $\leq 13$ $\mathrm{mg} / \mathrm{dL}$ in males, or $\leq 12 \mathrm{mg} / \mathrm{dL}$ in females) [12]; diabetes (glycemia $\geq 126 \mathrm{mg} / \mathrm{dL}$ ) [13]; hypercholesterolemia (total cholesterol $\geq 190 \mathrm{mg} / \mathrm{dL})$; altered HDL-cholesterol $(<40$ $\mathrm{mg} / \mathrm{dL}$ in males, or $<50 \mathrm{mg} / \mathrm{dL}$ in females), and hypertriglyceridemia (triglycerides $\geq 150 \mathrm{mg} / \mathrm{dL}$ ) [14]. The use of medication to control serum levels was also considered.

Dyslipidemia was defined according to the lipid fraction that was altered, triglycerides $\geq 150 \mathrm{mg} / \mathrm{dL}$, LDLcholesterol $\geq 160 \mathrm{mg} / \mathrm{dL}$, HDL-cholesterol $<40 \mathrm{mg} / \mathrm{dL}$ in males, or $<50 \mathrm{mg} / \mathrm{dL}$, in females [14].

For the definition of the metabolic syndrome, a combination of the presence of at least three components of glycemia $\geq 110 \mathrm{mg} / \mathrm{dL}$, systolic blood pressure $\geq 130$ $\mathrm{mmHg}$ and/or diastolic $\geq 85 \mathrm{mmHg}$, triglycerides $\geq 150$ $\mathrm{mg} / \mathrm{dL}$, HDL-cholesterol $<40 \mathrm{mg} / \mathrm{dL}$ in males, or $<50$ $\mathrm{mg} / \mathrm{dL}$ in females, and abdominal circumference $>102$ $\mathrm{cm}$ in males, and $>88 \mathrm{~cm}$, in females [15].

Hypertension was identified based on the mean of the second and third blood pressure measurements (systolic blood pressure $\geq 140 \mathrm{mmHg}$ and/or diastolic $\geq 90 \mathrm{mmHg}$ ) or based on the use of hypotensive medication [16].

The waist circumference, waist-to-hip ratio (WHR) and body mass index (BMI) were obtained as the mean of two repeated measures. In the case of waist circumference, measures $>102 \mathrm{~cm}$ in men and $>88 \mathrm{~cm}$ in women were considered very high. WHR, in turn, was considered high when values were $\geq 1.0$ in men and $\geq 0.85$ in women [17]. BMI was obtained as the ratio between weight $(\mathrm{kg})$ and the height squared $\left(\mathrm{m}^{2}\right)$. Specific cutoff points for BMI to older people were: $\mathrm{BMI}<22$ for low weight; BMI between 22 and 27 for eutrophic weight; and BMI > 27 for overweight [18].

\section{Statistical analysis}

Descriptive statistics were obtained focusing on measures of central tendency (mean and median) and 1st quintile of the Maximum HGS stratified by sex and age group (60-69, 70-79, and 80 or over). According to Fried [19], the 20th percentile of the Maximum HGS by sex and age group was adopted for the definition of low HGS and normal HGS, from which a description of the population was made through sociodemographic variables, life habits, and health conditions focusing on measures of absolute (observed $\mathrm{n}$ and expanded $\mathrm{N}$ for the population) and relative frequency, estimating the differences in the proportions among subjects classified with low HGS by the Pearson Chi-square test.

Thus, the Odds Ratio (logistic regression) models were used to estimate the associations between low HGS and health variables. Bivariate and multivariate analyses by sex estimated the magnitudes of association. The multivariate models, adjusted for covariables (sociodemographic, life habits, and health conditions) that were associated with the outcome of $p \leq 0.20$ in the bivariate 
analysis, were defined using the Enter method, with their respective confidence intervals at $95 \%(95 \% \mathrm{CI})$ by the Wald statistic. The models that best fit the data were determined using the Hosmer-Lemeshow test, the Akaike criterion, and the percent concordant. The significance level of $5 \%$ was adopted. Besides, in all the analyses the effect of the complex sample design and the weights of the observations were taken into account using the proc. survey routines of the statistical package $\mathrm{SAS}^{\oplus}$ version 9.3.

\section{Results}

The mean handgrip strength in older people was $27.2 \mathrm{~kg}$, and the mean difference between one age group and another, for example, 60-69 to $70-79$ and $70-79$ to $\geq 80$, was $-4.1 \mathrm{~kg}$, being these differences greater among men. The 20th percentile of HGS per age group in males ranged from $28.8 \mathrm{~kg}$ in the sexagenarians to $20.8 \mathrm{~kg}$ in the octogenarians. Among women, the 20th percentile of HGS ranged from $18.7 \mathrm{~kg}$ among 60-69years old to $12 \mathrm{~kg}$ among the oldest women, with a stronger difference between the ages of $70-79$ and 80 or more (Table 1 ).

In general, the prevalence of low HGS was $16.7 \%$ in men and $17.8 \%$ in women. At the intersection of the low HGS with sociodemographic and life habits variables, it was found the association with occupational physical activity in both men and women. There were also borderline associations of the level of HGS with physical activity in leisure among women and smoking among men (Table 2).

Regarding the analysis of associations between HGS (low vs. normal) and health/clinic conditions (Table 3), associations with the variables BMI, self-assessment of health in relation to people of the same age, IADL, and anemia were statistically significant in both sexes. Specifically, among women, it was observed that those who had insomnia had a significantly higher proportion of low HGS (23.0\%) than those without insomnia (14.4\%). Only, among men, the prevalence of low HGS was significantly higher in those who assessed their current health worse than it was 12 months before the interview, those with dependence in ADL, and those with diabetes. Additionally, borderline associations $(0.05<p<0.10)$ of HGS were identified with self-assessment of health and hypertriglyceridemia, among men, and with metabolic syndrome, among women.

Table 4 presents the results of the non-adjusted and adjusted logistic regression analyses, identifying the crude and independent effects of the factors associated with the occurrence of low HGS among older men and women. The odds of low HGS were significantly and consistently higher among older people with low weight (men: $\mathrm{aOR}=2.80$; 95\%CI: $1.19,6.61$; women: $\mathrm{aOR}=2.61$; $95 \% \mathrm{CI}: 1.46,4.66$ ) and with anemia (men: $\mathrm{aOR}=4.15$; 95\%CI: 2.09 , 8.21; women: $\mathrm{aOR}=1.80$; $95 \% \mathrm{CI}: 1.06,3.06$ ).

The presence of diabetes was found to be significantly associated with low HGS as a risk factor among men $(\mathrm{aOR}=1.95 ; 95 \% \mathrm{CI}: 1.00,3.81)$, having a partner $(\mathrm{aOR}=$ 2.44; 95\%CI: 1.32, 4.51); being a smoker or ex-smoker $(\mathrm{aOR}=3.25$; 95\%CI: $1.25,8.44)$; current self-assessment of health as worse than that of the previous 12 months ( $\mathrm{aOR}=2.21$; 95\%CI: $1.14,4.30)$; and presenting dependence in activities of daily living $(\mathrm{aOR}=2.92$; CI95\%: 1.35 , 6.30) were associated with low HGS in men. Among women, there were higher odds of occurrence of low HGS associated with altered WHR $(\mathrm{aOR}=1.79$; 95\%CI: $1.02,3.12)$, insomnia $(\mathrm{aOR}=1.83$; 95\%CI: 1.10, 3.03) and physical activity in displacement/occupational physical activity $(\mathrm{aOR}=1.75$; 95\%CI: $1.08,2.84)$.

\section{Discussion}

This work confirms the significant decrease of HGS in older men and women, generally indicating a steeper decline in men [4, 20], as well as an intensification of this decline with age in older women. It points out the consistency, in both sexes, of the association of low HGS with low weight and anemia. It also shows the extent to which sociodemographic and behavioral factors, as well as health conditions, are differently associated with low HGS among older men and women.

The option to define the low strength by the lower quintile of the HGS distribution by sex and also by age group (60, 70 and 80 years old or older) was justified by the identification, both among men and women, of a strong correlation of HGS with age [10], which allowed some neutralization of the effect of this variable in the analyses. Differently from the option adopted here, the

Table 1 Mean, median and 20th percentile of the maximum HGS among older people

\begin{tabular}{|c|c|c|c|c|c|c|c|c|c|}
\hline \multirow[t]{2}{*}{ Variables } & \multicolumn{3}{|l|}{$\underline{\text { Overall }}$} & \multicolumn{3}{|l|}{ Men } & \multicolumn{3}{|c|}{ Women } \\
\hline & Mean & Median & P20 & Mean & Median & P20 & Mean & Median & P20 \\
\hline Total & 27.2 & 25.0 & 18.9 & 33.6 & 33.1 & 25.0 & 21.6 & 20.6 & 16.8 \\
\hline \multicolumn{10}{|l|}{ Age (age group) } \\
\hline 60-69 years old & 29.4 & 27.4 & 20.0 & 36.4 & 36.6 & 28.8 & 23.3 & 21.9 & 18.7 \\
\hline 70-79 years old & 25.5 & 23.9 & 18.0 & 31.5 & 30.6 & 24.7 & 20.4 & 19.6 & 16.1 \\
\hline$\geq 80$ years old & 21.3 & 20.3 & 15.2 & 25.9 & 24.6 & 20.8 & 17.4 & 16.7 & 12.0 \\
\hline
\end{tabular}


Table 2 Prevalence of Low HGS by sex, according to sociodemographic characteristics and life habits among older people

\begin{tabular}{|c|c|c|c|c|c|c|c|c|c|c|c|c|}
\hline \multirow[t]{3}{*}{ Variables } & \multicolumn{4}{|c|}{ Overall } & \multicolumn{4}{|c|}{ Men } & \multicolumn{4}{|c|}{ Women } \\
\hline & \multicolumn{4}{|c|}{ Low HGS ( $\leq$ P20) } & \multicolumn{4}{|c|}{ Low HGS ( $\leq$ P20) } & \multicolumn{4}{|c|}{ Low HGS ( $\leq$ P20) } \\
\hline & $n$ & $\mathrm{~N}$ & $\%$ & $x^{2}$ & $\bar{n}$ & $\mathrm{~N}$ & $\%$ & $x^{2}$ & $n$ & $N$ & $\%$ & $x^{2}$ \\
\hline Total & 169 & 4054 & 17.3 & - & 66 & 1822 & 16.7 & - & 103 & 2232 & 17.8 & - \\
\hline Age (age group) & & & & 0.592 & & & & 0.751 & & & & 0.517 \\
\hline 60-69 years old & 78 & 2228 & 16.6 & & 31 & 1061 & 16.9 & & 47 & 1166 & 16.4 & \\
\hline 70-79years old & 58 & 1168 & 17,5 & & 21 & 468 & 15.2 & & 37 & 700 & 19.4 & \\
\hline$\geq 80$ years old & 33 & 658 & 19,7 & & 14 & 292 & 19.0 & & 19 & 365 & 20.4 & \\
\hline Referred skin color & & & & 0.705 & & & & 0.509 & & & & 0.810 \\
\hline White & 43 & 1023 & 18.3 & & 18 & 493 & 19.7 & & 25 & 530 & 17.1 & \\
\hline Non-white & 126 & 3031 & 17.0 & & 48 & 1329 & 15.8 & & 78 & 1702 & 18.0 & \\
\hline Marital status ${ }^{a}$ & & & & 0.122 & & & & 0.087 & & & & 0.587 \\
\hline With partner & 53 & 1323 & 14.7 & & 28 & 736 & 13.7 & & 25 & 587 & 16.2 & \\
\hline Without partner & 115 & 2712 & 19.0 & & 38 & 1086 & 20.0 & & 77 & 1626 & 18.4 & \\
\hline Education & & & & 0.045 & & & & 0.155 & & & & 0.137 \\
\hline Illiterate & 71 & 1678 & 20.7 & & 27 & 733 & 19.5 & & 44 & 944 & 21.8 & \\
\hline Elementary School & 80 & 1955 & 17.3 & & 34 & 960 & 17.7 & & 46 & 995 & 16.9 & \\
\hline High School & 18 & 421 & 11.0 & & 5 & 129 & 8.0 & & 13 & 293 & 13.2 & \\
\hline Physical activity in leisure ${ }^{a}$ & & & & 0.007 & & & & 0.100 & & & & 0.056 \\
\hline Active & 6 & 155 & 6.9 & & 3 & 88 & 7.6 & & 3 & 67 & 6.0 & \\
\hline Sedentary & 161 & 3857 & 18.6 & & 61 & 1693 & 17.7 & & 100 & 2164 & 19.4 & \\
\hline Occupational Physical Activity or in Displacement & & & & 0.007 & & & & 0.052 & & & & 0.014 \\
\hline Active & 57 & 1415 & 13.3 & & 19 & 531 & 12.2 & & 38 & 884 & 14.1 & \\
\hline Sedentary & 112 & 2638 & 20.6 & & 47 & 1291 & 19.7 & & 65 & 1347 & 21.6 & \\
\hline Screen time per day ${ }^{a}$ & & & & 0.984 & & & & 0.974 & & & & 0.962 \\
\hline Up to $3 \mathrm{~h}$ & 119 & 2927 & 17.1 & & 47 & 1334 & 16.3 & & 72 & 1592 & 17.8 & \\
\hline More than $3 \mathrm{~h}$ & 46 & 1034 & 17.1 & & 16 & 413 & 16.4 & & 30 & 620 & 17.7 & \\
\hline Smoking & & & & 0,073 & & & & 0.065 & & & & 0.417 \\
\hline Non-smoker & 20 & 500 & 11.7 & & 9 & 258 & 9.9 & & 11 & 242 & 14.4 & \\
\hline Smoker, ex-smoker & 149 & 3553 & 18.6 & & 57 & 1564 & 18.9 & & 92 & 1989 & 18.4 & \\
\hline Alcohol consumption ${ }^{a}$ & & & & 0,193 & & & & 0.234 & & & & 0.690 \\
\hline No & 152 & 3580 & 17.8 & & 55 & 1497 & 11.0 & & 97 & 2083 & 14.7 & \\
\hline Yes & 9 & 255 & 11.8 & & 6 & 182 & 17.4 & & 3 & 73 & 18.0 & \\
\hline
\end{tabular}

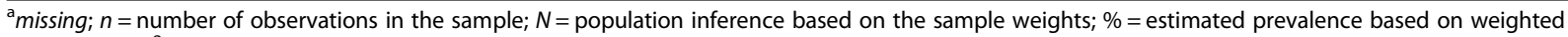
frequencies; $\mathrm{X}^{2}=p$-value of the Pearson Chi-square test

use of the 20th percentile of HGS adjusted by sex and BMI has been recommended to define low HGS, especially in studies about the frailty phenotype [19]. However, if the 20th percentile of HGS of the entire older population had been adopted, disregarding age ranges, more than $50 \%$ of men and women over 80 would be classified as having low HGS, and only a small number of youngestold would be identified as 'weak', which would probably lead to important changes in the results presented here.

BMI is used as a criterion for the definition of nutritional status, and the associations between low weight and low HGS shown here agree with well-established evidence [21]. Hand dynamometry has been recognized as a useful marker of functionality as well as an objective marker of malnutrition [22, 23].

Studies with inpatients revealed that HGS is a reliable measure for the prediction of malnutrition, resulting in more extended hospitalization, clinical complications, and death [23]. Functional losses related to malnutrition can be recovered after protein uptake, and hand dynamometry captures these changes with improved strength levels more rapidly than the BMI [24], which is an alternative for the BMI between the criteria for assessing nutritional status in geriatric patients [25]. 
Table 3 Prevalence of Low HGS by sex, according to health conditions among older people

\begin{tabular}{|c|c|c|c|c|c|c|c|c|c|c|c|c|}
\hline \multirow[t]{3}{*}{ Variables } & \multicolumn{4}{|c|}{ Overall } & \multicolumn{4}{|c|}{ Men } & \multicolumn{4}{|c|}{ Women } \\
\hline & \multicolumn{4}{|c|}{ Low HGS $(\leq P 20)$} & \multicolumn{4}{|c|}{ Low HGS $(\leq P 20)$} & \multicolumn{4}{|c|}{ Low HGS ( $(\leq P 20)$} \\
\hline & $n$ & $N$ & $\%$ & $x^{2}$ & $n$ & $\mathrm{~N}$ & $\%$ & $x^{2}$ & $n$ & $N$ & $\%$ & $x^{2}$ \\
\hline Waist circumference $^{a}$ & & & & 0.652 & & & & 0.249 & & & & 0.956 \\
\hline Normal & 106 & 2627 & 17.5 & & 57 & 1561 & 17.6 & & 49 & 1066 & 17.2 & \\
\hline Altered & 60 & 1362 & 16.4 & & 9 & 261 & 13.2 & & 51 & 1101 & 17.5 & \\
\hline Waist-to-hip ratio ${ }^{a}$ & & & & 0.200 & & & & 0.629 & & & & 0.187 \\
\hline Normal & 65 & 1647 & 15.4 & & 39 & 1082 & 15.9 & & 26 & 565 & 14.6 & \\
\hline Altered & 100 & 2319 & 18.5 & & 26 & 717 & 18.0 & & 74 & 1602 & 18.8 & \\
\hline$\left.B M\right|^{*}$ & & & & $<0.001$ & & & & 0.035 & & & & $<0.001$ \\
\hline Low weight & 41 & 926 & 31.8 & & 16 & 389 & 30.9 & & 25 & 537 & 32.4 & \\
\hline Eutrophic & 56 & 1400 & 15.8 & & 26 & 771 & 15.9 & & 30 & 629 & 15.8 & \\
\hline Overweight & 67 & 1599 & 14.2 & & 23 & 625 & 13.5 & & 44 & 974 & 14.6 & \\
\hline Self-assessment of health & & & & 0.080 & & & & 0.077 & & & & 0.540 \\
\hline Very Good /Good /Regular & 135 & 3231 & 16.4 & & 54 & 1483 & 15.4 & & 81 & 1749 & 17.3 & \\
\hline Bad Nery bad & 34 & 822 & 22.3 & & 12 & 339 & 26.6 & & 22 & 483 & 20.0 & \\
\hline $\begin{array}{l}\text { Assessment of current health in relation to that of the previous } 12 \\
\text { months }^{\text {a }}\end{array}$ & & & & 0.011 & & & & 0.006 & & & & 0.398 \\
\hline Better /Equal & 101 & 2391 & 15.1 & & 38 & 1040 & 13.3 & & 63 & 1352 & 16.8 & \\
\hline Worse & 68 & 1662 & 22.2 & & 28 & 782 & 26.0 & & 40 & 880 & 19.7 & \\
\hline Assessment of health in comparison with people of the same age ${ }^{a}$ & & & & $<0.001$ & & & & 0.005 & & & & 0.020 \\
\hline Better /Equal & 119 & 2814 & 15.2 & & 46 & 1227 & 14.1 & & 73 & 1587 & 16.2 & \\
\hline Worse & 44 & 1090 & 27.5 & & 17 & 507 & 28.4 & & 27 & 583 & 26.8 & \\
\hline Dependence in $\mathrm{ADL}^{\mathrm{a}}$ & & & & 0.035 & & & & $<0.001$ & & & & 0.830 \\
\hline No & 139 & 3338 & 16.3 & & 49 & 1363 & 14.5 & & 90 & 1975 & 17.9 & \\
\hline Yes & 29 & 692 & 24.5 & & 17 & 459 & 32.4 & & 12 & 233 & 16.6 & \\
\hline Dependence on IADL ${ }^{a}$ & & & & $<0.001$ & & & & $<0.001$ & & & & 0.032 \\
\hline No & 59 & 1492 & 12.3 & & 24 & 693 & 11.3 & & 35 & 799 & 13.3 & \\
\hline Yes & 109 & 2537 & 22.8 & & 42 & 1129 & 24.0 & & 67 & 1408 & 21.9 & \\
\hline Depression in the GDS* & & & & 0.094 & & & & 0.246 & & & & 0.269 \\
\hline No & 104 & 2506 & 15.9 & & 44 & 1213 & 15.4 & & 60 & 1293 & 20.5 & \\
\hline Yes & 64 & 1514 & 20.3 & & 21 & 576 & 20.1 & & 43 & 938 & 16.4 & \\
\hline Insomnia ${ }^{a}$ & & & & 0.024 & & & & 0.347 & & & & 0.015 \\
\hline No & 97 & 2310 & 15.0 & & 45 & 1225 & 15.5 & & 52 & 1085 & 14.4 & \\
\hline Yes & 72 & 1744 & 21.9 & & 21 & 597 & 19.9 & & 51 & 1147 & 23.0 & \\
\hline Musculoskeletal complaints & & & & 0.733 & & & & 0.701 & & & & 0.335 \\
\hline No & 70 & 1722 & 16.8 & & 41 & 1099 & 17.4 & & 29 & 623 & 15.7 & \\
\hline Yes & 99 & 2332 & 17.7 & & 25 & 723 & 15.8 & & 74 & 1609 & 18.8 & \\
\hline Cardiovascular event & & & & 0.203 & & & & 0.509 & & & & 0.171 \\
\hline No & 125 & 2992 & 16.5 & & 50 & 1368 & 16.0 & & 75 & 1625 & 16.9 & \\
\hline Yes & 44 & 1061 & 20.2 & & 16 & 454 & 19.2 & & 28 & 607 & 21.1 & \\
\hline Anemia $^{a}$ & & & & $<0.001$ & & & & $<0.001$ & & & & 0.022 \\
\hline No & 107 & 2573 & 13.8 & & 35 & 1010 & 11.9 & & 72 & 1563 & 15.4 & \\
\hline Yes & 56 & 1355 & 30.3 & & 30 & 791 & 35.1 & & 26 & 564 & 25.3 & \\
\hline
\end{tabular}


Table 3 Prevalence of Low HGS by sex, according to health conditions among older people (Continued)

\begin{tabular}{|c|c|c|c|c|c|c|c|c|c|c|c|c|}
\hline \multirow[t]{3}{*}{ Variables } & \multicolumn{4}{|c|}{ Overall } & \multicolumn{4}{|c|}{ Men } & \multicolumn{4}{|c|}{ Women } \\
\hline & \multicolumn{4}{|c|}{ Low HGS $(\leq P 20)$} & \multicolumn{4}{|c|}{ Low HGS $(\leq P 20)$} & \multicolumn{4}{|c|}{ Low HGS ( $\leq$ P20) } \\
\hline & $\mathrm{n}$ & $\mathrm{N}$ & $\%$ & $x^{2}$ & $\mathrm{n}$ & $\mathrm{N}$ & $\%$ & $x^{2}$ & $\mathrm{n}$ & $\mathrm{N}$ & $\%$ & $x^{2}$ \\
\hline Diabetes $^{a}$ & & & & & & & & 0.046 & & & & 0.191 \\
\hline No & 138 & 3277 & 17.0 & & 51 & 1393 & 15.3 & & 87 & 1884 & 18.4 & \\
\hline Yes & 28 & 712 & 18.1 & & 14 & 407 & 24.0 & & 14 & 305 & 13.6 & \\
\hline Hypertension $^{a}$ & & & & 0.190 & & & & 0.195 & & & & 0.733 \\
\hline No & 48 & 1165 & 20.0 & & 22 & 585 & 21.1 & & 26 & 580 & 18.9 & \\
\hline Yes & 120 & 2867 & 16.5 & & 43 & 1216 & 15.3 & & 77 & 1651 & 17.6 & \\
\hline Hypercholesterolemia a & & & & 0.261 & & & & 0.875 & & & & 0.107 \\
\hline No & 86 & 2056 & 18.3 & & 39 & 1039 & 16.8 & & 47 & 1017 & 20.1 & \\
\hline Yes & 78 & 1891 & 15.7 & & 26 & 762 & 16.3 & & 52 & 1129 & 15.3 & \\
\hline Altered HDL cholesterol ${ }^{a}$ & & & & 0.090 & & & & 0.404 & & & & 0.176 \\
\hline No & 105 & 2579 & 15.7 & & 45 & 1269 & 15.7 & & 60 & 1311 & 15.8 & \\
\hline Yes & 58 & 1349 & 19.8 & & 20 & 532 & 19.6 & & 38 & 817 & 19.9 & \\
\hline Hypertriglyceridemia $^{\text {a }}$ & & & & 0.033 & & & & 0.054 & & & & 0.287 \\
\hline No & 103 & 2480 & 19.5 & & 47 & 1256 & 19.9 & & 56 & 1224 & 19.1 & \\
\hline Yes & 62 & 1491 & 14.1 & & 18 & 544 & 12.0 & & 44 & 946 & 15.6 & \\
\hline Dyslipidemia $^{\text {a }}$ & & & & 0.280 & & & & 0.265 & & & & 0.563 \\
\hline No & 38 & 951 & 20.4 & & 22 & 595 & 20.7 & & 16 & 356 & 19.9 & \\
\hline Yes & 127 & 3020 & 16.2 & & 43 & 1206 & 15.1 & & 84 & 1814 & 17.0 & \\
\hline Metabolic syndrome ${ }^{a}$ & & & & 0.080 & & & & 0.386 & & & & 0.173 \\
\hline No & 91 & 2213 & 18.9 & & 35 & 989 & 18.5 & & 56 & 1224 & 19.2 & \\
\hline Yes & 71 & 1690 & 14.8 & & 29 & 790 & 14.8 & & 42 & 900 & 14.9 & \\
\hline
\end{tabular}

${ }^{a}$ missing; $n=$ number of observations in the sample; $N=$ population inference based on weights and sampling design; $\%=$ estimated prevalence based on weighted frequencies; $x^{2}=p$-value of the Pearson chi-square test

Anemia has a multifactorial etiology and, in the older people, contributes to morbidities, physical performance reduction, and the increase in the number of falls, frailty, dementia, hospitalization, and mortality [26]. Identifying the association of HGS with anemia, consistently among men and women, in the general population, ratifies previous findings where reduced hemoglobin levels were linked to low HGS and other criteria of frailty and physical disabilities in the elderly community [27].

This study also confirms that the effect of anemia on the occurrence of low HGS is independent of other sociodemographic, anthropometric, and clinical factors [28]. Although a possible link between reduced HGS and the multiple etiological factors of anemia beyond the scope of the present study is recognized, a plausible explanation for the findings is that the reduction of hemoglobin levels decreases the oxygen consumption capacity of the muscles, leading to tissue hypoxia that promotes the decline of physiological reserve [29].

The relationship between low HGS and diabetes had already been reported in a previous study conducted in Rio Branco among adults aged 18-96, where men with weak HGS presented odds of occurrence of self-reported disease four times higher than those with normal HGS [7]. In this sense, this research contributes to confirming this relationship, considering diabetes diagnosed in the laboratory.

The literature predominantly establishes positive association between the level of HGS and the prevalence of diabetes among men and women [30,31]. Regarding the association of HGS with the incidence of diabetes, prospective studies are contradictory [32, 33]. The association of HGS with diabetes may be justified by its intimate connection with muscle mass, which plays an important role in the use of blood glucose, also due to its size and responsiveness to insulin [34].

Other explanatory factors of the variation in the occurrence of low HGS had significant effects only in one sex or the other.

Among men, having a partner resulted in a risk factor for low HGS. Although the mechanisms of these associations are unclear, the marital situation is likely a proxy of something that is closely related to HGS, which may reflect accommodation greater preference for household 
Table 4 Logistic regression of the low HGS ( $\leq$ P20) with independent variables, by sex, among older people

\begin{tabular}{|c|c|c|c|c|}
\hline \multirow[t]{2}{*}{ Variables } & \multicolumn{2}{|l|}{ Men } & \multicolumn{2}{|l|}{ Women } \\
\hline & OR (C195\%) Crude & OR (C195\%) Adjusted & OR (C195\%) Crude & OR (C195\%) Adjusted \\
\hline Marital status (With vs. Without partner) & $1.57(0.91,2.70)$ & $2.44(1.32,4.51)$ & - & - \\
\hline Smoking (Smoker /Ex-smoker vs. Non-smoker) & $2.11(0.89,4.97)$ & $3.25(1.25,8.44)$ & - & - \\
\hline $\begin{array}{l}\text { Assessment of current health in relation to that of the previous } \\
12 \text { months (Worse vs. Better /Equal) }\end{array}$ & $2.28(1.23,4.21)$ & $2.21(1.14,4.30)$ & - & - \\
\hline ADL (Dependent vs. Independent) & $2.83(1.63,4.93)$ & $2.92(1.35,6.30)$ & - & - \\
\hline \multicolumn{5}{|l|}{ BMI } \\
\hline Low weight & $2.38(1.07,5.27)$ & $2.80(1.19,6.61)$ & $2.56(1.49,4.33)$ & $2.61(1.46,4.66)$ \\
\hline Eutrophic & 1 & 1 & 1 & 1 \\
\hline Overweight & $0.83(0.44,1.57)$ & $1.09(0.50,2.38)$ & $0.91(0.91,1.32)$ & $0.86(0.58,1.26)$ \\
\hline Anemia (Yes vs. No) & $4.01(2.14,7.51)$ & $4.15(2.09,8.21)$ & $1.86(1.08,3.22)$ & $1.80(1.06,3.06)$ \\
\hline Diabetes (Yes vs. No) & $1.75(0.98,3.12)$ & $1.95(1.00,3.81)$ & $0.70(0.40,1.23)$ & $0.53(0.28,1.01)$ \\
\hline Insomnia (Yes vs. No) & - & - & $1.77(1.09,2.89)$ & $1.83(1.10,3.03)$ \\
\hline Waist-to-hip ratio (Altered vs. Normal) & - & - & $1.35(0.85,2.14)$ & $1.79(1.02,3.12)$ \\
\hline $\begin{array}{l}\text { Physical activity in displacement /occupational physical activity } \\
\text { (Yes vs. No) }\end{array}$ & - & - & $1.67(1.09,2.56)$ & $1.75(1.08,2.84)$ \\
\hline$p$-value (Wald) & & $<0.001$ & & $<0.001$ \\
\hline \% Concordance & & 76.0 & & 67.4 \\
\hline
\end{tabular}

$\%$ Concordance is a fitness quality criterion of the logistic regression model

habits, sedentarism, among others. However, in the same sense, it was reported that being married was associated with lower HGS [4] among men aged 72, although a protective effect of marriage on strength has been found among young and middle-aged adults $[4,35]$. Studies are needed to explore better the relationships between HGS and marital status in different age groups, since this relationship is little-known.

The smoking history was another factor that was independently associated with the occurrence of low HGS only among men. Smoking had a high prevalence in the study population, especially among women, and the finding that this habit among them did not related to the low HGS is remarkable. Therefore, this is worthy of the exploration in future studies. The relationships of smoking with detrimental health effects are already widely recognized, and it has already been identified in previous studies that smoking men have reduced HGS compared to non-smoking peers [36]. As a possible explanation for the mechanisms underlying muscle reduction among smokers, a review has gathered evidence that the constituents of circulating cigarette smoke seem to play an important role in this process, since they induce loss of muscle mass, reduce oxygen supply, and impair mitochondrial function [37].

The decline in physiological reserve caused by aging leads to a loss of functional independence - a central aspect of the health of older people. The literature has broadly established a relationship between low HGS and dependence in ADL among men and women [38-40] but has been less consistent in establishing the relationship with IADL [39, 40]. In any case, the measurement of HGS as a useful tool in the identification of people at risk of future functional decline has been sustained [41]. The findings of this study only confirm, among men, the association between low HGS and dependence on ADL, regardless of other factors.

Furthermore, the assessment of the current health as worse than 12 previous months ago was relevant to the explanation of the variation in the occurrence of low HGS among men. Although self-assessment of health is an indicator of objective physical and mental health conditions, its use in HGS studies is unknown. However, parallel relations support the consideration of the variable and greater exploitation of its effects in different contexts [42]. It is worth mentioning that this study explored self-assessment with three distinct but correlated indicators, as well as the finding that self-assessment of health is a construct that differs between the sexes, with unequal health profiles of men and women being influenced by their perceptions [20].

Among women, in addition to reduced BMI, the presence of anemia and absence of diabetes were independently associated with increased chances of low HGS, altered WHR score, insomnia, and inadequate physical activity in displacement and/or occupational activity.

WHR is an indirect measure of central adiposity, and the accumulation of visceral fat is responsible for the concentration of inflammatory mediators that can result in sarcopenia and frailty, which may explain the association of altered WHR and reduced HGS among women [43]. 
Although insomnia was considered based on selfreport, its association with low HGS finds resonance in other studies [44, 45], although it has presented a relation only among women. A recent study with middleaged and older people demonstrated a quadratic relationship in which both reduced hours of sleep in both sexes and excessive sleep in women were associated with a steeper decline in HGS over four years of follow-up. One possible explanation on the relationship between sleep and HGS is in the circadian clock, where sleep hours and sleep quality act in musculoskeletal physiology, regulating and being influenced by sleep, by genetic mechanisms and inflammatory processes, which are also associated with loss of strength [45].

Among the limitations of the present research, it must be emphasized a possible attenuation of the associations due to the survival effect. Also, the punctual diagnosis of the diseases, both those defined by physical examinations, such as hypertension, and those resulting from clinical laboratory tests from blood dosage that could falsify results, was somehow mitigated by broad guidance on the protocols to carry out the examinations and evaluations. On the other hand, as a strong point of this study, it should be noted that its results are inferential to the older population of the capital of the state of Acre and that laboratory and clinical measures were used to define the diseases, which allowed to inform people who were unaware of the presence of certain diseases, either by limitation or lack of access to health services or even by a lack of awareness of the need for such care.

\section{Conclusion}

Factors associated with low HGS are not equal between the sexes. Among older men, low HGS was associated with low weight (BMI), anemia, diabetes, having a partner, having smoking history, negative self-assessment of current health compared to the previous 12 months, and dependence in ADL. Among older women, low HGS was associated with low weight (BMI), anemia, diabetes (surprisingly, a protective effect was observed here), altered waist-to-hip ratio, insomnia, and insufficient physical activity in displacement or occupational tasks.

The findings reinforce HGS as a health biomarker in older people of both sexes and support its use as a viable strategy which can easily be incorporated into both rehabilitation and primary health care, not only for the screening of the low strength as an indicator of health problems in older people but as a measure, along with other criteria, for monitoring health throughout life, thus allowing promising early intervention actions in disease prevention and health promotion.

\section{Abbreviations}

IADL: Instrumental Activities of Daily Living; ADL: Activities of Daily Living: DC: Demographic Census; GDS: Geriatric Depression Scale; EDOC-l: Study of
Chronic Diseases - Older People; HGS: Handgrip Strength; HDL-cholesterol: High Density Lipoproteins-Cholesterol; IBGE: Brazilian Institute of Geography and Statistics; Cl: Confidence Interval; BMI: Body Mass Index; OR: Odds Ratio; aOR: Adjusted Odds Ratio; WHR: Waist-to-Hip Ratio; ×2: Pearson's Chi-square test

\section{Acknowledgments}

No applicable.

\section{Authors' contributions}

CAA conceptualization, data curation, formal analysis, funding acquisition, investigation, methodology, validation, writing - original draft, writing review \& editing. TLMA conceptualization, data curation, funding acquisition, investigation, methodology, project administration, resources, supervision, validation, writing - review \& editing. GTRM conceptualization, funding acquisition, methodology, project administration, resources, supervision, writing - review \& editing. MTLV conceptualization, data curation, methodology, supervision, validation, writing - review \& editing. MCP formal analysis, methodology, supervision, validation, writing - original draft, writing - review \& editing. All authors read and approved the final manuscript.

\section{Funding}

The operating expenses for data collection, exclusively, were sponsored by Conselho Nacional de Desenvolvimento Científico e Tecnológico [CNPq - Call MCTI/CNPQ/MS-SCTIE-DECIT 06/2013, for supporting strategic research for the Health System by the Brazilian Network for Health Technology Assessment (REBRATS), 401081/Process 2013-3]; and Fundação de Amparo à Pesquisa do Acre [FAPAC - Call PPSUS 001/2013, of the Research Program for SUS: shared health management (MS/CNPq/FAPAC/SESACRE), Process 606814-0000029 and Call PPSUS 001/2015, of the Research Program for SUS: shared health management (MS/CNPq/FAPAC/SESACRE), Process 6068-150000640]. The article-processing charge was financed by the Coordenação de Aperfeiçoamento de Pessoal de Nível Superior - Brasil (CAPES) - Finance Code 001

\section{Availability of data and materials}

The datasets used for this study are available from the corresponding author upon reasonable request.

\section{Ethics approval and consent to participate}

The basic research project, EDOC, was approved by the Research Ethics Committee (REC) of the Federal University of Acre under the number 17543013.0.0000.5010, all participants signed the Informed Consent Term. This study, specifically, was also approved by the REC of the Sérgio Arouca National School of Public Health, number 50895015.2.0000.5240.

Consent for publication

Not applicable.

\section{Competing interests}

The authors declare that they have no competing interests.

\section{Author details}

${ }^{1}$ Federal Institute of Education, Science and Technology of Acre, Rio Branco, AC, Brazil. ${ }^{2}$ Center for Health Sciences and Sports, Federal University of Acre, Rio Branco, AC, Brazil. ${ }^{3}$ Department of Epidemiological and Quantitative Methods in Health, National School of Public Health Sergio Arouca, Oswaldo Cruz Foundation, Rio de Janeiro, RJ, Brazil. ${ }^{4}$ National School of Statistical Sciences, Brazilian Institute of Geography and Statistics, Rio de Janeiro, RJ, Brazil. ${ }^{5}$ Department of Health Administration and Planning, National School of Public Health Sergio Arouca, Oswaldo Cruz Foundation, Rio de Janeiro, RJ, Brazil.

Received: 27 September 2019 Accepted: 11 March 2020

Published online: 26 March 2020

References

1. Tieland M, Trouwborst I, Clark BC. Skeletal muscle performance and ageing. J Cachexia Sarcopenia Muscle. 2018:9:3-19.

2. Sayer AA, Kirkwood TBL. Grip strength and mortality: a biomarker of ageing? Lancet. 2015:386:226-7.

3. Pedersen BK. Muscle as a secretory organ. Compr Physiol. 2013;3:1337-62. 
4. Sternäng $\mathrm{O}$, Reynolds $C A$, Finkel $D$, Ernsth-Bravell $M$, Pedersen $N L$, Aslan AKD. Factors associated with grip strength decline in older adults. Age Ageing. 2015:44:269-74.

5. Bohannon RW. Hand-grip dynamometry predicts future outcomes in aging adults. J Geriatr Phys Ther. 2008;31:3-10.

6. Wilson D, Jackson T, Sapey E, Lord JM. Frailty and sarcopenia: the potential role of an aged immune system. Ageing Res Rev. 2017;36:1-10.

7. Amaral CA, Portela MC, Muniz PT, Farias ES, Araújo TS, Souza OF. Association of handgrip strength with self-reported diseases in adults in Rio Branco, acre state, Brazil: a population-based study. Cad Saúde Pública. 2015;31:1313-25.

8. Lino VTS, Rodrigues NCP, O'Dwyer G, MK de N A, Mattos IE, Portela MC. Handgrip strength and factors associated in poor elderly assisted at a primary care unit in Rio de Janeiro, Brazil. PLoS ONE. 2016;11:e0166373.

9. Amaral TLM, Amaral CA, Portela MC, Monteiro GTR, Vasconcellos MTL. Study of chronic diseases (Edoc): methodological aspects. Rev Saúde Pública. 2019;53:8.

10. Amaral CA, Amaral TLM, Monteiro GTR, Vasconcellos MTL, Portela MC. Hand grip strength: reference values for adults and elderly people of Rio Branco, acre, Brazil. PLos One. 2019;14:e0211452

11. Almeida OP, Almeida SA. Reliability of the Brazilian version of the geriatric depression scale (GDS) short form. Arq Neuropsiquiatr. 1999;57:421-6.

12. Organización Mundial de la Salud. Concentraciones de hemoglobina para diagnosticar la anemia y evaluar su gravedad [Internet]. Ginebra: Organización Mundial de la Salud; 2011. Available from: http://www.who. int/vmnis/indicators/haemoglob [cited 2015 Jun 3].

13. American Diabetes Association. Diagnosis and classification of diabetes mellitus. Diabetes Care. 2014;37:\$81-90.

14. Faludi AA, MC de O I, JFK S, APM C, Bianco HT, Afiune Neto A, et al. Atualização da Diretriz Brasileira de Dislipidemias e Prevenção da Aterosclerose - 2017. Arq Bras Cardiol. 2017;109:1-76.

15. Sociedade Brasileira de Hipertensão, Sociedade Brasileira de Cardiologia, Sociedade Brasileira de Endocrinologia e Metabologia, Sociedade Brasileira de Diabetes, Associação Brasileira para Estudos da Obesidade. I Diretriz Brasileira de Diagnóstico e Tratamento da Síndrome Metabólica. Arq Bras Cardiol. 2005;84:3-28.

16. Malachias MVB, M a. M G, Nobre F, Alessi A, Feitosa AD, Coelho EB, et al. 7th Brazilian guideline of arterial hypertension: chapter 2 - diagnosis and classification. Arq Bras Cardiol. 2016;107:7-13.

17. World Health Organization. Obesity: preventing and managing the global epidemic [Internet]. Geneva: World Health Organization; 2000. Available from: http://www.who.int/nutrition/publications/obesity/WHO_TRS_894/en/ [cited 2013 Mar 9].

18. Lipschitz DA. Screening for nutritional status in the elderly. Prim Care. 1994; 21:55-67.

19. Fried LP, Tangen CM, Walston J, Newman AB, Hirsch C, Gottdiener J, et al. Frailty in older adults evidence for a phenotype. J Gerontol Ser A. 2001;56:M146-57.

20. Oksuzyan A, Gumà J, Doblhammer G. Sex differences in health and survival. Demogr Perspect Gend Fam health Eur [internet]. Springer, Cham; 2018. p. 65-100. Available from: https://doi.org/https://doi.org/10.1007/978-3-31972356-3_5 [cited 2018 mar 7].

21. Oumi M, Miyoshi M, Yamamoto T. Ultrastructural changes and glutathione depletion in the skeletal muscle induced by protein malnutrition. Ultrastruct Pathol. 2001;25:431-6.

22. Bharadwaj S, Ginoya S, Tandon P, Gohel TD, Guirguis J, Vallabh H, et al. Malnutrition: laboratory markers vs nutritional assessment. Gastroenterol Rep. 2016;4:272-80.

23. Gaikwad NR, Gupta SJ, Samarth AR, Sankalecha TH. Handgrip dynamometry: a surrogate marker of malnutrition to predict the prognosis in alcoholic liver disease. Ann Gastroenterol Q Publ Hell Soc Gastroenterol. 2016;29:509-14.

24. Schlüssel MM, Anjos LA, Kac G. Hand grip strength test and its use in nutritional assessment. Rev Nutr. 2008:21:233-5.

25. Kizilarslanoglu MC, Kilic MK, Gokce D, Sakalar T, Ulger Z. Is it possible using handgrip strength instead of body mass index in MNA-SF test to assess the nutritional status of geriatric patients? J Nutr Health Aging. 2017;21:579-84.

26. Milagres CS, Franceschini SDCC, Priore SE, Lima LM, Ribeiro AQ. Prevalência e etiologia da anemia em idosos: uma revisão integral. Med Ribeirao Preto Online. 2015:48:99.

27. Silva JC, ZV de M, Silva C, S de B M, Guariento ME, Neri AL, et al. Understanding red blood cell parameters in the context of the frailty phenotype: interpretations of the FIBRA (Frailty in Brazilian Seniors) study. Arch Gerontol Geriatr. 2014;59:636-41.
28. Cecchi F, Pancani S, Vannetti F, Boni R, Castagnoli C, Paperini A, et al. Hemoglobin concentration is associated with self-reported disability and reduced physical performance in a community dwelling population of nonagenarians: the Mugello study. Intern Emerg Med. 2017;12:1167-73.

29. Chaves PHM. Functional outcomes of anemia in older adults. Semin Hematol. 2008:45:255-60.

30. Mainous AG, Tanner RJ, Anton SD, Jo A. Low grip strength and prediabetes in normal-weight adults. J Am Board Fam Med. 2016;29:280-2.

31. Peterson MD, McGrath R, Zhang P, Markides KS, Snih SA, Wong R. Muscle weakness is associated with diabetes in older Mexicans: the Mexican health and aging study. J Am Med Dir Assoc. 2016;17:933-8.

32. Leong DP, Teo KK, Rangarajan S, Lopez-Jaramillo P, Avezum A Jr, Orlandin $A$, et al. Prognostic value of grip strength: findings from the prospective urban rural epidemiology (PURE) study. Lancet. 2015;386:266-73.

33. Li JJ, Wittert GA, Vincent A, Atlantis E, Shi Z, Appleton SL, et al. Muscle grip strength predicts incident type 2 diabetes: population-based cohort study. Metabolism. 2016;65:883-92.

34. Arvandi M, Strasser B, Meisinger C, Volaklis K, Gothe RM, Siebert U, et al. Gender differences in the association between grip strength and mortality in older adults: results from the KORA-age study. BMC Geriatr. 2016;16.

35. Guralnik JM, Butterworth S, Patel K, Mishra G, Kuh D. Reduced midlife physical functioning among never married and childless men: evidence from the 1946 British birth cohort study. Aging Clin Exp Res. 2009;21:174-81.

36. Al-Obaidi S, Al-Sayegh N, Nadar M. Smoking impact on grip strength and fatigue resistance: implications for exercise and hand therapy practice. J Phys Act Health. 2014;11:1025-31.

37. Degens H, Gayan-Ramirez G, van Hees HWH. Smoking-induced skeletal muscle dysfunction. From evidence to mechanisms. Am J Respir Crit Care Med. 2015;191:620-5.

38. Kim M-J, Yabushita N, Kim M-K, Matsuo T, Okuno J, Tanaka K. Alternative items for identifying hierarchical levels of physical disability by using physical performance tests in women aged 75 years and older. Geriatr Gerontol Int. 2010:10:302-10.

39. Taekema DG, Gussekloo J, Maier AB, Westendorp RGJ, Craen D, AJ M. Handgrip strength as a predictor of functional, psychological and social health. A prospective population-based study among the oldest old. Age Ageing. 2010;39:331-7.

40. Yang M, Ding X, Luo L, Hao Q, Dong B. Disability associated with obesity, dynapenia and dynapenic-obesity in Chinese older adults. J Am Med Dir Assoc. 2014;15:150.e11-6.

41. Kim M, Tanaka K. A multidimensional assessment of physical performance for older Japanese people with community-based long-term care needs. Aging Clin Exp Res. 2014;26:269-78.

42. Sousa-Santos AR, Afonso C, Moreira P, Padrão P, Santos A, Borges N, et al. Weakness: the most frequent criterion among pre-frail and frail older Portuguese. Arch Gerontol Geriatr. 2018;74:162-8.

43. Castillo C, Carnicero JA, de la Torre MÁ, Amor S, Guadalupe-Grau A, RodríguezMañas L, et al. Nonlinear relationship between waist to hip ratio, weight and strength in elders: is gender the key? Biogerontology. 2015;16:685-92.

44. Auyeung TW, Kwok T, Leung J, Lee JSW, Ohlsson C, Vandenput L, et al. Sleep Duration and Disturbances Were Associated With Testosterone Level, Muscle Mass, and Muscle Strength--A Cross-Sectional Study in 1274 Older Men. J Am Med Dir Assoc. 2015;16:630.e1-6.

45. Wang TY, Wu Y, Wang T, Li Y, Zhang D. A prospective study on the association of sleep duration with grip strength among middle-aged and older Chinese. Exp Gerontol. 2018;103:88-93.

\section{Publisher's Note}

Springer Nature remains neutral with regard to jurisdictional claims in published maps and institutional affiliations. 